\title{
ŞEYH GÂLİB'İN ŞİIRLERİNDE BİR ANLATIM ÖZELLİĞİ
}

\author{
DR. ABDULKADİR GÜRER
}

Divan şiirinde bir şairin şahsî üslûbu hakkında söylenebilecek çok az söz vardır. Hatta bu alanda yapılmış çalışmaların ve araştırmaların sağladığı bilgi birikimiyle bir şairin değil, belki bir dönemin, bütün bir edebî anlayışın üslûbundan söz etmek mümkün olabilir. Üslûbun şairin dilden seçtiği kelimeleri yan yana getirişindeki sır veya büyü olduğunu kabul etsek bile, bu yan yana gelişin hangi şairin muhayyilesinde şekillendiğini tespit edebilmek son derece güç, hatta bazan imkânsızdır. Meselâ bu satırların yazarı, XVIII. yüzyıl divan şairlerinden Es'ad-1 Bağdâdî'nin,

Nigehüñ mest-i mey-i nahvet ü nāz oldı yine

Āfet-i cān u dil-i ehl-i niyãz oldı yine

beytindeki ${ }^{1}$ teşbihte soyuttan somuta geçişin muhteşem bir örneği olan "mest-i mey-i nahvet ü nāz"dan hareketle onun Hint üslûbunun bir özelliğini şiirlerinde başarıyla uygulayan bir şair olduğuna veya Şeyh Gâlib'in,

Tefe' 'ül eyledüm ol āfetüñ çeşm-i siyāhından

Sevād-1 ḥarf-i vaḥşet geldi dỉvān-1 nigāhından

Ḥarir-i şu`leye tebdīl idüp libās-1 teni

Fenāda añladı zevḳ-i hulūd pervāne

beyitlerindeki "dīvān-1 nigāh" ve "harīr-i şu‘ le" gibi teşbihlerden yola çıkarak onun şiirlerinde orijinal benzetmelerin ve eşsiz hayallerin

\footnotetext{
${ }^{1}$ Es'ad-1 Bağdâdî, Dîvân-1 Es'ad, şahsî kitaplarım arasındaki nüsha, Yk. 69b.
} 
varlığına hükmedebilir ${ }^{2}$; hatta bu şairlerin söz konusu başarılarının sırını araştırmaya da kalkışabilir. Ancak Es'ad'ın başarısının sırrı, Fehîm-i Kadîm'in Dîvârłındaki bir "muaşşer"in,

Ey nigāh-1 gazabı mest-i mey-i nahvet ü nāz

mısraında ${ }^{3}$; Gâlib'in başarısının sırn ise, Fehim'den daha uzaklarda Şevket-i Buharînnin Divarıındaki,

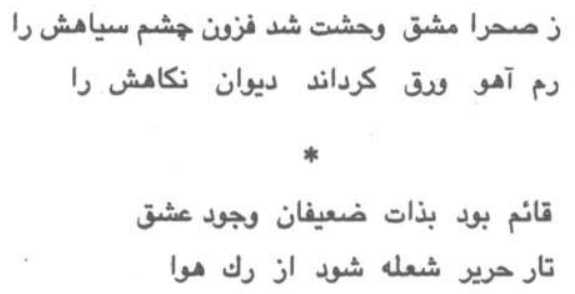

beyitlerinde gizlidir ${ }^{4}$. Bir şairin şiirlerinin gerçek değerinden söz edebilmenin ancak onun şiirlerindeki orijinal teşbihlerin, istiarelerin ve buna bağlı olarak orijinal hayallerin tespitiyle mümkün olabileceği gerçeğinden hareket edersek, Fehîm-i Kadîm'in ve Şevket-i Buharînin bu başarılarının sırrının başka divanların yaprakları arasında gizlenmiş

${ }^{2}$ Şeyh Gâlib, Divan-ı Gâlib. (Gazeliyyât), Mısır, 1252 (Gâlib Divanı), s. $94 ; 110$.

${ }^{3}$ Tahir Uzgör (Dr.); Fehîm-i Kadîm ,Hayat, Sanat, Dîvân'ı ve Metnin Bugünkü Türkçesi, Atatürk Kültür, Dil ve Tarih Yüksek Kurumu Atatürk Kültür Merkezi Yayını-Sayı: 44, Ankara, 1991, s. 264.

${ }^{4}$ Şevket-i Buhârî, Divan-ı Şevket, Dil ve Tarih-Coğrafya Fakültesi Ktp. Yazmaları, M. Con A, No. 94 (Dîvân-1 Şevket), yk. 41a; 2a. Beyitlerin Türkçeye çevirisi:

1. Sahrada (yaşayan vahşîler)dan onun vahşet dersine talep o kadar çok ki, ahu sürüsü (bile) sürekli onun bakış divanını okumakla meşgul; yani o güzel o kadar vahşî ve ürkek bakışlara sahip ki, ahular bile ondan bakış ögreniyorlar.

2. Nasıl alev ipeğinin arışları haṿanın damarlarına yerleşirse, aşkın varlığı da ancak zayıfların zatında kaim olur. 
olup olmadığını söyleyebilmek ise, ancak karşılaştırmalı edebiyat araştırmalarının öneminin anlaşılmasıyla mümkün olabilecek, divan edebiyatının bir sanat olarak tekâmül çizgisini de belirgin hâle getirecek olan bu araştırmalar yapılmadan divan şiiri hakkında verilecek olumlu ya da olumsuz her hüküm büyük ölçüde tartışllabilir olma özelliğini muhafaza edecektir 5 .

Artık anlaşılması gereken. bir diğer gerçek de Şeyhî'nin, Fuzûlî'nin, Bakî'nin şiirleri için uygulanan klâsik şerh yönteminin divan edebiyatının bütün dönemlerine meselâ Nâilînnin, Sâmî'nin, Şeyh Gâlib'in şiirleri için; açıkça söyleyelim, Irak ve Azerbaycan üslûpları için uygulanan Sûdîlerin, Sürûrîlerin şerh yöntemlerinin Hint

${ }^{5}$ Prof. Dr. Ali Nihad Tarlan'ın Şeyhî Divanı'nı Tetkik adlı eseri hariç tutulursa, divan edebiyatı araștırmalarında bu bakımdan gelinen nokta pek de iç açıcı değildir. Bu edebiyatta orijinal mecazların, istiarelerin bunlara bağlı olarak şairlerin orijinal hayalleri bir yana, divanlarda tazminen kullanılmış beyitlerin, mısraların bile şairleri henüz tespit edilememiştir. $\mathrm{Bu}$ tür çalışmaların yapılmamasının doğurabileceği sonuçlara en ilginç örnek herhâlde İstanbul Büyükșehir Belediyesi Kültür İșleri Daire Başkanlığı tarafindan 16-18 Mart 1995 tarihleri arasında düzenlenen "Şeyh Galip Sempozyumu"nun sonunda bir değerlendirme konuşması yapan Sayın Prof. Talat Halman'ın Gâlib'in Ahmet Paşa Dîvân'ndan tazminen bir müseddesinde kullandığı beyti, Șeyh Gâlib'e ait sanarak "dünya çapında bir beyit" ilan etmesidir. Konuşmanın bu bölümünü buraya aynen aktarıyorum: "Kelimeleri anlamasak bile o seslerin öyle bir musikisi var ki, okumak zorundayız:

İsterim hüsnün gibi cevrine pāyān olmasin

Tek seni sevmek cihan halkına āsān olmasın

$\mathrm{Bu}$ dünya çapında bir beyittir. Kuruluşuyla da, düşüncesiyle de Şeyh Gâlib'in şiirinde velveleler var, manevi zelzeleler var, büyük sarsıntılar var ve bunların getirdiği muhteşem bir orkestra sesi var." [Şeyh Galib Kitabı, İstanbul Büyükş̧ehir Belediyesi Kültür İşleri Daire Başkanlığı Yayınları, No. 18, İstanbul, 1995, s. 192; Ali Nihad Tarlan (Prof. Dr.), Ahmed Paşa Divanı, Milli Eğitim Bakanlı̆ı Yayınları, İstanbul, 1996, s. 285; Şeyh Gâlib, Dîvân, s. 228]. 
üslûbu için uygulanmasının mümkün olamayacağıdır ${ }^{6}$. Sözü edilen klâsik şerh yönteminin Hint üslûbu özellikleri taşıyan bir beyte uygulanmasıyla ortaya çıkan sonucun beyitteki üslûp özelliklerini yansıtmaktan ne kadar uzak olduğunu göstermek için en karakteristik örnek herhâlde Şeyh Gâlib'in,

Gūyā ḩayāl-i haț̣t-1 lebüñle müjemde huun

Bāg̀-1 vefâda ț̣țîi-i zenbürdur baña

beyti için yapılan şerhtir. Bu şerhin uzantılarını bir yana bırakarak beytin nesre çevirisini vermekle yetiniyorum: "Dudağının etrafını çevreleyen ayva tüyleri hayali ile kirpiğimdeki kan benim için sanki vefa bağında geveze bir papağandır ${ }^{7}$." Dikkat edilirse, şârihinin beytin şerhinde şiir dilinden düz yazıya aktarmakta zorlandığı, hatta çok uzak çağrışımlardan yararlanarak divan şiiri tekniği açısından oldukça anlamsız bir çeviri olan "geveze bir papağan"la karşıladığı ibarenin "țūțī-i zenbūr" olduğu hemen anlaşılacaktır. Ancak, ilk bakışta fesahat kusurlarından "ta'kîd-i ma'nevî"ye örnek gösterilebilecek derecede kapalı görünen bu beyti düz yazıya aktarmadaki, daha doğrusu anlamadaki güçlüğün temel sebebini şarihin yetersizliğinde değil, onun uyguladığı klâsik şerh yönteminin farklı bir üslûpla yazılmış bu beytin izahı için geçersiz bir yöntem oluşunda aramak gerekir. Şimdi beytin yalnızca nesre çeviri kısmını verdiğim söz konusu şerhini bir tarafa bırakarak beyitteki "țütí-i zenbür" tamlamasıla şairin neyi kastetmiş olabilececeğine bakmak istiyorum:

Bu tamlamanın her iki unsuru da isimdir. "Ṭūți", Farsça "tūtī" kelimesinin "mu'arreb"i olup şiirde "leb"in bilinen, alışılmış "müşebbehün bih"lerindendir. Tamlamanın ikinci unsuru olan "zenbür" ise, Arapça aslı "zünbür" olan kelimenin Farsçada kullanılan

${ }^{6}$ Irak, Azerbaycan ve Hint üslûpları için bkz. Sîrûs Şemîsâ (Dr.), Sebkşinâŝi-i Şi' ${ }^{\top}$, Tahran (tarihsiz), s. 192-269; 284-303.

${ }^{7}$ Prof. Dr. Ali Nihad Tarlan'ın Makalelerinden Seçmeler, Haz. Müjgân Cumbur(Dr.), Atatürk Kültür, Dil ve Tarih Yüksek Kurumu Atatürk Kültür Merkezi Yayını, Sayı: 45, Ankara, 1990, s. 113-114; Gâlib Dîvânt (Gazeliyyât), s. 2. 
şeklidir ve "arı" anlamındadır. Arapça, Farsça ve Türkçe sözlüklerde "zenbür"un "geveze" veya buna yakın bir anlamı bulunmadığı gibi, sıfat olarak kullanıldığına dair bir bilgi de mevcut değildir. İki ismin Farsçada teşkil edebileceği tamlama türü "izâfet-i lâmiyye", "izâfet-i beyâniyye", "izâfet-i isti'ârî" ve "izâfet-i teşbîhî"den ibaret olduğuna ve bu tamlamayı "izâfet-i lâmiyye", "izâfet-i beyâniyye" ya da "izâfet-i isti'ârî" olarak değerlendirmek mümkün olamayacağına göre, "izâfet-i teşbîhî" olma ihtimali üzerinde durmak gerekir ki, "zenbür" ile "țūțī" arasında bilinen bir benzetme yönünün (:vech-i şebeh) bulunmaması sebebiyle ilk bakışta bu ihtimal de mümkün görünmemektedir. $O$ hâlde şair için tahayyül kudretinin her şeyin üstünde olduğunu,

Bu söze Kưr'ān gibi ỉmān ider ehl-i sühnan

Şā‘i irüñ Ġālib tahayyül rütbe-i i cāzıdur

mısralarıyla ifade eden Şeyh Gâlib'in tamamen yeni ve orijinal bir hayaliyle karşı karşıya bulunduğumuzu ve beyte farklı bir gözle bakmak mecburiyetinde olduğumuzu kabul etmek durumundayı $z^{8}$.

Beytin yapısına dikkat edilirse, birinci mısra ile ikinci mısra arasında paralel bir anlatımın mevcut olduğu, bu paralel anlatımın da "leb" ile "țūți" ve "haț̣t" ile "zenbūr" arasındaki teşbihlerle sağlandığı görülecektir. Bu iki teşbihten birincisinde "leb" "müşebbeh", "țuțị" "müşebbehün bih"tir ve bu teşbihin benzetme yönü malûmdur. $\mathrm{O}$ hâlde beytin anlamının düğümlendiği nokta, "müşebbeh"i "haț̣", "müşebbehün bih"i "zenbūr" ve Gâlib'den önce yaşamış şairlerin divanlarında bir başka örneğine rastlayamadığımız için benzetme yönü bizce meçhul, yani sadece şairin muhayyilesinde gizli olan ikinci teşbihtir. Gâlib'in Divar'ına baş vuracak olursak, söz konusu teşbihin ilk bakışta bir muamma gibi görünen bu benzetme yönünün onun,

\footnotetext{
${ }^{8}$ Gâlib Divanı(Gazeliyyāt), s.28.
} 
Rūzumı tỉre iderse şebümi rūşen ider

Dūd-1 āhum gibidür hatțt-1 siyeh-fām baña

Rūzumı tỉre iderse haț-1 sebzi o mehüñ

Bir felek mihr-i münevver virür ahş̧ām baña

gibi beyitlerde "rūz" ve "şeb", "rūz" ve "ahşām" tezatlarıyla ifade ettiği düşünceyle, yani "hatț"ın âşı için iticiliği ve divan edebiyatı "güzel"inin güzelliği üzerindeki olumsuz etkisiyle bağlantılı olduğunu görürüz". Kısaca Gâlib, bu beyitte "leb"in çekiciliğiyle "hatț" in iticiliği arasında yaşadığı ruh hâlini ifade etmek için "ḩațț" " "zenbûr"a teşbih etmek suretiyle yeni ve orijinal bir "müşebbehün bih" elde etmiş; "hatț" "müşebbehün bih"lerinden biri olan "țuțị"yi "izâfet-i teşbîhî" yoluyla bir arada kullanarak yeni bir hayale, daha doğrusu bir hayal tezadına ulaşmışıı' ${ }^{10}$. Gâlib, bu beyitte "ḩațț-1 leb"i "bâg ge-1 vefâ"ya girmeye, yani "vuslat"a engel adeta yarısı arı, yarısı papağan mitolojik bir yaratık gibi tasvir etmektedir ki kanımca bu, korku ve ümit arasındaki karmaşık duyguların alışılmamış bir teşbihle şiire yansımasıdır. Gâlib'in XIX. yüzyılda hayalde ve üslûpta en büyük izleyicisi olan Keçecizâde İzzet Molla'nın

Nüş-1 lebiyle niş̧-i ' itābın ḩayāl idüp

Ol gül-' izār țūtịi-i zenbūrdur baña

beyti de onun söz konusu tezatlı anlatımı ile ilgili olarak burada ileri sürülen görüşleri doğrulayıcı bir mahiyet gösterir ${ }^{11}$. Gâlib'in söz konusu hayalini bu beytinde küçük değişikliklerle fakat, güçlü sanatkârlara mahsus, ancak "ilmâm" kabul edilecek bir tasarrufla ifade eden İzzet Molla, önce beytin birinci mısraında iki müreşşah istiareyle

${ }^{9}$ Gâlib Divanı, (Gazeliyyât), s.3.

${ }^{10} \mathrm{Bu}$ üslûp özelliği için bk. Şiblî-i Nu'mânî, Şi'rü'l- 'acem yâ Târîh-i Şu'arâ ve Edebiyyât-ı Îrân, Hintçeden Farsçaya Çeviren: Seyyid Muhammed Takî, Tahran, 1343 HŞ., C.II, s.35.

${ }^{11}$ İzzet Molla, Dîvân-ı Bahâr-ı Efkâr (Gazeliyyât), Bulak, 1255, s.3. 
"leb"i "țūți"ye "“itāb"1 da "zenbūr"a teşbih etmiş; sonra beytin ikinci mısraında bu kapalı istiarelerin "müşebbehün bih"lerini açığa çıkarmak ve aynı "izâfet-i teşbîhî"nin "müşebbeh" ve "müşebbehün bih"leri olarak kullanmak suretiyle son derece başarılı bir tezatlı anlatım sağlamıştır' ${ }^{12}$ Aynı hayali bir "terkîb-bend"inin

Ḥikmet-i Ḥaḳk'ı her eşyāda beyān eyleyerek Șūret-i ț̣utịi-i zenbūra girüp lāl oldum

beytinde kullanmayı deneyen Esrar Dede ise, Gâlib'in bu tezatlı hayalini anlamakta İzzet Molla kadar başarılı olamamış, "sâlik"in "İlâhî tecellî" karşısında "hayret"e düşerek "lâl" olma hâlini Gâlib'in ve İzzet Molla'nın beyitlerinden anlaşıldığına göre, "maşûk"un sıfatı olması gereken "ṭuṭîi-i zenbür"la ifade ederek bir hayal hatasına düşmüştür ${ }^{13}$.

Gâlib'in söz konusu beytinin yer aldığı, her beyti tasavvufí “seyr ü sülûk"ün bir mertebesini, bir makamını tazammun eden,

'Așk āteş-i tecellī-i Manșūr'dur baña

Her çūp-1 dār bir şecer-i Ṭür'dur baña

matlalı gazelin bir bütün hâlinde ifade ettiği tasavvufî düşünce (=mazmun) göz önünde bulundurulursa, bu beytin manevî yolculuğun mertebelerinden biri olan "havf" ve "recâ" ile ilgili olduğunu anlamak hiç de güç olmayacaktır ${ }^{14}$. Nitekim XVII. yüzyıl şairlerinde Nev'îzâde Atâyî'nin

La' liyle hațț havf u recāda ḳodı bizi

Medhūş-1 cām-1 'işve vü ḥayrān-1 vuṣlatuz

beyti, tasavvufi birer sembol olarak "hatț"in "havf"1 ve "leb"in

12 "İlmâm" için bk. Tâhirü'l-Mevlevî, Edebiyat Lügati, Enderun Kitabevi, İstanbul, 1973; Hüseyn Vâ'iz-i Kâşifî, Bedâyi 'ü'l-efkâr fi-Sanâyi'i'l-eş'âr, Dil ve Tarih-Coğrafya Fakültesi Yazmaları, İ.Saib I Koleksiyonu, No: 452, yk.143a

${ }^{13}$ Osman Horata (Doç.Dr.), Esrâr Dede, Hayatı-Eserleri, Şïr Dünyası ve Divanı, T.C. Kültür Bakanlığı yayınları, No: 2103, Ankara, 1998, s.219.

${ }^{14}$ İsmâ'îl-i Ankaravî, Minhâcü'l-fukarâ (Minhâc), s.155-159 
"recā"yı ifade ettiğini tereddüte yer bırakmayacak şekilde ispat için yeterli bir kanıttır ${ }^{15}$. Çünki âşık, yani salik için vuslatın son engeli demek olan "ḩaț̣" varlıktan, "mâsivâ"dan hâlâ bir nişâne, "leb" ise, vuslat demek olan yokluk, yani "adem" mertebesidir.

"Hुaț̣"ın belirmesi "âşık" için bir olumsuz unsur olmasına, onu "havf" içinde bırakmasına karşılık, vuslatın da en büyük habercisidir. Nitekim hat gelince "bāg-1 vefâ"ya girmenin yani vuslatın mümkün olacağı veya "maşuk"un vuslat "va'd"ini yerine getireceği de yine Gâlib'in,

Gelmeyince ḩaṭ mükāfăt-1 sitem emr-i muhāāl

Āh ile ruhssāre-i șubḥı siyāh itmek de güç

Miyān-1 nükte-şināsān-1 fenn-i ' aş̣̣ında

Cevāz-1 vușlata haț̣̂ndan intiḳāl olınur

Nấzı 'uşşāḳa niyāzı yāra taḳír itdi huaṭ

Geldi hükkm-i sābıḳı hep nesh ü tağyīi itdi ḩaț

gibi beyitlerinde ifadesini bulmuştur ${ }^{16}$.

Gâlib'in Dîvân'ından söz konusu tezatlı anlatıma bir başka örnek de,

Ġālib ḳalemüñ eyle siper tīg-i zebāna

Hูāmūş-1 süḩan-gūy ile nã-dān idemez baḥs

beytindeki "hāmūş-1 sühan-gūy" terkibidir. Gâlib bu beytinde de iki zıt anlamlı kelimeyi, aynı sıfat tamlaması içinde bir arada kullanmak suretiyle birinci mısradaki "kalem"i ifade etmiştir" ${ }^{17}$ Yine şairin,

\footnotetext{
${ }^{15}$ Nev'î-zâde Atâyî, Dîvân-l Atâŷ̀, Süleymaniye Ktp., Es'ad Ef. Kitaplanı, No:2872/7, yk 211b.

${ }^{16}$ Gâlib Dîvânı, s.17, 24, 61 .

${ }^{17}$ Gâlib Dîvânı, s.16.
} 
Lisān-1 ḥāldür minḳār-1 mürğ-i şem'e pervāne

Sühan-sāz-1 hamūşi hem-zebān ister mi ister yā

Lāl-i ‘aşḳa ḳuvvet-i güftār-1 hāmūşīi nedür

Ḥayret-i vașluñla her mūyum zebān olsun da gör

beyitlerindeki "sühan-sāz-1 hamūşi”" ve "güftār-1 hāmūşī" terkipleri de bu üslûp özelliğinin onun şiirlerine birer yansımaları olarak gösterilebilirr $^{18} \mathrm{Bu}$ beyitlerde ifade edilmek istenen düşüncenin Mevlevî tarikatinin "rükn-i a'zam"1 olduğu bizzat Gâlib tarafindan Şerh-i Cezîre-i Mesnevî de ifade edilen "samt" veya "hâmûş̂̀" ile ilgili olduğunu da burada hatırlamak gerekir" ${ }^{19}$. Onun bir müsemmeninin,

Belā mevc-āver-i gird-āb-1 ḥayret nāhudā nā-būd

'Adem sāḥillerin dutdı dirìgā bang-i nā-mevcūd

mısralarındaki "bāng-i nā-mevcūd" tezadında da Mevlevî tarikatinin bu en önemli rüknüne işaret vardır ${ }^{20}$.

Gâlib'in bir beytinin şerhi münasebetiyle düşüncelerimi açıkladığım Hint üslûbuna ait bu anlatım özelliği onun ve diğer Hint üslûbu şairlerinin daha çok soyut, dolayısıyla tasavvufî kavramları ifadede baş vurduğu bir anlatım yoludur. Nitekim Hint üslûbunun Fars şiirindeki en güçlü temsilcilerinden biri olan Şevket-i Buhārî,

$$
\text { جامه عريان تنى يك عمر بس باشـ مالم مرا }
$$

beytinde "cāme-i 'uryān-tenī" ile tasavvufî bir kavram olan "terk ve

${ }^{18}$ Gâlib Dîvânı (Gazeliyyât), s.3, 34 .

${ }^{19}$ Gâlib Dîvânı, s.34; Şeyh Gâlib, Şerh-i Cezîre-i Mesnevî, Dil ve TarihCoğrafya Fakültesi Kütüphanesi Yazmaları, M.Ozak I, No: 541, yk. 3b; Aynı konuda bkz. Minhâc, s.38, 78-79.

${ }^{20}$ Gâlib Dîvânı (Kasâid), s.358. 
tecerrüd"ü ifade etmiştir ${ }^{21}$.

Sonuç olarak diyebiliriz ki, yukarıdan beri örneklerini vererek izaha çalıştığım, bir düşünceyi, bir hayali, bir kavramı zıddıyla ifade etmek diye tanımlayabileceğimiz bu üslûp özelliği, Mevlânâ Celâleddîn-i Rûmî'nin Hint üslûbunun bir edebî akım olarak meydana çıkışından yüzyıllarca önce,

$$
\text { هر كبوتر مى برد زى جانبى }
$$

beytindeki "cānib-i bī-cānibī" ile soyut ve tasavvufî bir kavram olan "lâ-mekân"1 ifade etmiş olmasından da anlaşılacağı gibi, tasavvuf şiirinin Hint üslûbuna miras bıraktığı soyut özellikle tasavvufí kavramları ifadede eşsiz bir anlatım yoludur ${ }^{22}$.

Şeyh Gâlib'e ait bir hayal olmamakla birlikte felsefî zemini ne olursa olsun aynı üslûp özelliğinin onun şiirindeki örneklerinden biri olan,

Görür nür-1 siyehden çeşme-i äb-1 hayātı ol Sevād-1 dīde-i ehl-i naẓardur halḳa-i tevhịid

beytindeki "nür-1 siyeh" ise, ayrı bir yazıya konu olacak kadar divan şiirinde yaygın ve farklı bir kullanıma sahiptir ${ }^{23}$.

21 Dîvân-l Şevket, yk. 44b; Beytin Türkçe çevirisi: Dünya halkının elbise(masiva)lerinden yüzümü ç̧evirdim. Çıplaklık elbisesi (terk ve tecerrüd) bir ömrün mahsulü olarak bana yeter.

${ }^{22}$ Muhammed Rızâ Şefî'î Kedkenî, Şâ 'ir-i Âyinehâ, Tahran, HŞ., 1366, s.55; Beytin Türkçeye çevirisi: Her güvercin bir yönden uçuyor; bu güvercin ise, yönsüzlük yönünden.

${ }^{23}$ Gâlib Dîvânı (Gazeliyyât), s.30. 